\title{
Usos da Terra e Áreas de Preservação Permanente (APP) na Bacia do Rio da Prata, Castelo-ES
}

\author{
Luciano Melo Coutinho ${ }^{1}$, Sidney Sára Zanetti ${ }^{2}$, Roberto Avelino Cecílio ${ }^{2}$, \\ Giovanni de Oliveira Garcia ${ }^{3}$, Alexandre Cândido Xavier ${ }^{3}$ \\ ${ }^{1}$ Curso de Ciências Biológicas, Centro Universitário São Camilo-ES, Cachoeiro de Itapemirim/ES, Brasil \\ ${ }^{2}$ Departamento de Ciências Florestais e da Madeira, Universidade Federal do Espírito Santo - UFES, \\ Jerônimo Monteiro/ES, Brasil \\ ${ }^{3}$ Departamento de Engenharia Rural, Universidade Federal do Espírito Santo - UFES, Alegre/ES, Brasil
}

\begin{abstract}
RESUMO
Este trabalho avaliou o uso da terra e identificou Áreas de Preservação Permanente (APPs) na Bacia Hidrográfica do Rio da Prata (BRP), município de Castelo-ES, via técnicas de geoprocessamento. A BRP é marcada pela supressão de vegetação nativa, para expansão da fronteira agropecuária. As classes de uso da terra foram vetorizadas por fotointerpretação de aerofotos ortorretificadas. A delimitação das APPs foi realizada a partir de dados de hidrografia e altimetria de cartas topográficas digitais, com respeito às determinações do Código Florestal Brasileiro. A principal forma de uso da terra é a agropecuária (60,84\% da área total), composta pela agricultura $(30,21 \%)$ e pela pecuária $(30,63 \%)$, sendo que a área preservada com floresta nativa é de $36,85 \%$. As APPs representam $55,48 \%$ da área total e sua maior parte $(50,40 \%)$ é utilizada para fins socioeconômicos, enquanto a cobertura florestal representa apenas $49,60 \%$.
\end{abstract}

Palavras-chave: manejo de bacias hidrográficas, uso e ocupação do solo, Áreas de Proteção Ambiental (APP), Bacia do Rio da Prata (ES).

\section{Land Use and Permanent Preservation Areas (PPA) in the Watershed of Rio da Prata, Brazil}

\begin{abstract}
In this study, we evaluated the use of land and identified the Permanent Preservation Areas (PPA) in the watershed of Rio da Prata (RPW) in the municipality of Castelo, Espirito Santo state, using geoprocessing techniques. RPW is marked by the removal of native vegetation for the expansion of the agricultural frontier. The classes of land use were vectored by photointerpretation of orthorectified aerial photographs. The delimitation of the PPAs was carried out based on hydrography and altimetry data from digital topographic maps according to the determinations of the Brazilian Forest Code. The main forms of land use are agriculture $(30.21 \%)$ and livestock $(30.63 \%)$, totaling $60.84 \%$ of the area, and the preserved area of native forest occupies $36.85 \%$ of the total area. The PPAs represent $55.48 \%$ of the total area, with most of it (50.40\%) being used for socioeconomic purposes, while the forestry cover represents only $49.60 \%$.
\end{abstract}

Keywords: watershed management, land use and occupancy, Environmental Protection Areas (EPA), Rio da Prata watershed. 


\section{INTRODUÇÃO}

No Brasil, o processo histórico de ocupação do território consistiu na substituição da cobertura florestal nativa por atividades agropecuárias, frequentemente baseando-se na exploração excessiva dos recursos naturais, desconsiderando sua importância ambiental e a sustentabilidade. Tal processo foi responsável por diversos problemas ambientais, destacando-se a significativa redução da qualidade dos solos e a intensificação da erosão hídrica, associados à diminuição da disponibilidade quantitativa e qualitativa dos recursos hídricos.

A supressão da vegetação nativa para a expansão da fronteira agropecuária - ou a sua substituição por outros tipos de uso da terra - tem agravado o processo da fragmentação florestal e provocado consequências negativas nos diferentes compartimentos da natureza, afetando, consequentemente, muitas espécies da fauna e da flora (Soares et al., 2011), além de afetar, também, o próprio homem.

Processos hidrológicos dinâmicos em bacias podem sofrer modificações significativas em decorrência de atividades antrópicas, como modificações na ocupação das terras, desmatamento, expansão da agropecuária e urbanização intensiva. Estas atividades modificam a dinâmica hidrológica em razão das alterações nas características de cobertura e perfil do solo, podendo ocasionar prejuízos diversos, como erosão, assoreamento e enchentes. Portanto, o uso da terra, com alteração da cobertura vegetal, constitui-se num dos fatores mais importantes que afetam a produção de água em áreas rurais (Lima, 2008), e é considerado, dessa forma, um importante foco de atuação do manejo de bacias hidrográficas.

A caracterização do meio físico da bacia hidrográfica, com o intuito de levantar todas as áreas críticas do ponto de vista da manutenção da água, é condição básica para um planejamento bem sucedido de conservação e produção de água. Segundo Lima (2008), a conservação da água não pode ser conseguida independentemente da conservação dos outros recursos naturais, pois o comportamento da fase terrestre do ciclo hidrológico reflete diretamente as condições e os tipos de uso dos terrenos.
Com o intuito de disciplinar e limitar as interferências antrópicas negativas sobre o meio ambiente, o Código Florestal Brasileiro - Lei n. ${ }^{\circ} 4.771$, de 15 de setembro de 1965 (Brasil, 1965), contemplou a criação das Áreas de Preservação Permanente (APPs). Nessas áreas, se preconiza a manutenção da cobertura florestal nativa, a fim de que esta desempenhe importantes funções ambientais, como a preservação dos recursos hídricos, da paisagem, da estabilidade geológica, da biodiversidade e do fluxo gênico de fauna e flora, além de proteger o solo contra a ação do processo erosivo e assegurar o bem-estar das populações humanas. A Resolução n. ${ }^{\circ}$ 303, do Conselho Nacional do Meio Ambiente (CONAMA) (Brasil, 2002), estabeleceu os parâmetros, definições e limites referentes às APPs, e adotou, ainda que implicitamente, a bacia hidrográfica como unidade de sua aplicação (Ribeiro et al., 2005).

O mapeamento das APPs é importante para o planejamento territorial, a fiscalização e as ações de campo nos âmbitos local, regional ou nacional, facilitando as fiscalizações que visam ao cumprimento da legislação ambiental (Hott et al., 2004; Eugenio et al., 2011). Segundo Ribeiro et al. (2005), a inexistência de demarcação oficial das áreas das APPs é um dos fatores que facilitam o descumprimento da legislação que as criou, levando à ocupação e à utilização ilegal dessas áreas.

Nos últimos anos, segundo Soares et al. (2011), as geotecnologias têm sido amplamente utilizadas no mapeamento e no monitoramento dos recursos naturais terrestres, se destacando como uma alternativa mais viável e que permite agilizar estes processos (Eugenio et al., 2011). Prova disso, é a existência, na literatura científica brasileira, de diversos artigos recentes que citam a utilização de geotecnologias para o mapeamento automático de APPs, como Eugenio et al. (2011), Soares et al. (2011), Vieira et al. (2011), Louzada et al. (2009), Nascimento et al. (2005), Pinto et al. (2005), Ribeiro et al. (2005) e Hott et al. (2004).

A partir do exposto, o presente trabalho teve como objetivos avaliar o uso da terra e identificar APPs na sub-bacia hidrográfica do Rio da Prata, Município de Castelo-ES, utilizando técnicas de sensoriamento remoto e geoprocessamento em ambiente de Sistemas de Informações Geográficas 
(SIG). Espera-se que tais procedimentos e resultados venham contribuir na geração de dados a serem aplicados na gestão da área e fornecer subsídios às tomadas de decisão, tendo em vista que, na atualidade, faz-se necessário adotar medidas que garantam a preservação dos recursos naturais.

\section{MATERIAL E MÉTODOS}

A área de estudo consistiu na sub-bacia hidrográfica do Rio da Prata (BRP), contida na Bacia Hidrográfica do Rio Itapemirim. A BRP possui área total de $132,28 \mathrm{~km}^{2}$ e localiza-se no município de Castelo, Macrorregião Sul do Estado do Espírito Santo (Figura 1). A precipitação anual na região varia entre 1.500 e $2.000 \mathrm{~mm}$, sendo o clima do tipo quente e úmido, com chuvas de verão (Aw), pela classificação de Köppen.

De acordo com RADAMBRASIL (Brasil, 1983), os principais solos da região são Argissolo, Chernossolo,
Cambissolo Álico e Latossolo Vermelho-Amarelo Álico. Silva (1993) e Castro Júnior et al. (2007) classificaram o relevo regional em: Faixa de Agradação Cachoeiro de Itapemirim - Castelo (altitude entre 80 e $100 \mathrm{~m}$; superfícies suaves, vales abertos e interflúvios abaulados; ação intempérica e raros afloramentos rochosos), Feições de Mar de Morros (altitude entre 200 e 900 m; tipos mais resistentes ao intemperismo) e Remanescentes do Ciclo Sul-Americano (altitudes em torno de 900 m; área de solos espessos, com processos erosivos em franco desenvolvimento).

A BRP representa satisfatoriamente as condições ambientais da Macrorregião Sul do Estado do Espírito Santo, sendo composta por diversidade paisagística natural e pela diversidade de atividades humanas, incluindo pecuária, silvicultura, culturas agrícolas permanentes e temporárias, muitas vezes em áreas que deveriam ser destinadas à preservação permanente. As principais atividades econômicas
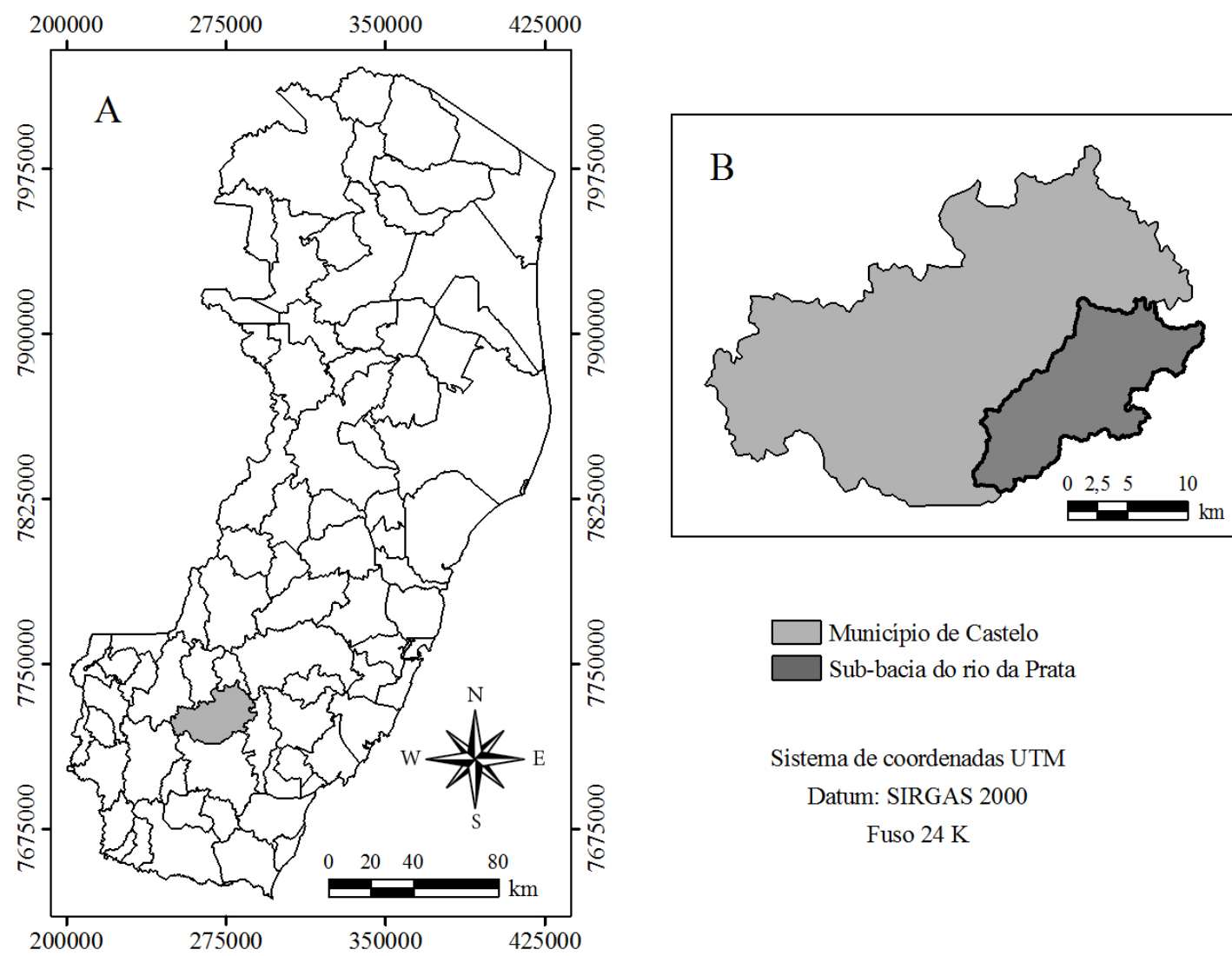

Figura 1. Localização da sub-bacia hidrográfica do rio da Prata: A) divisão política do estado do Espírito Santo; B) no município de Castelo.

Figure 1. Location of Prata river watershed: A) Espírito Santo state policy division, Brazil; B) at Castelo county. 
são a mineração, a agropecuária e o turismo (Vicente et al., 2005). Essa sub-bacia é um exemplo de área rural que passou pelo processo histórico e ocupacional marcado pela imigração europeia, como ocorreu em grande parte do Brasil.

As classes de uso e cobertura do solo na BRP foram identificadas e delimitadas a partir de fotointerpretação, utilizando fotografias aéreas ortorretificadas, com vetorização manual na tela do computador (digitalização de linhas), pela edição de um arquivo Shapefile com formato de polígono. As fotografias aéreas, de junho/2007, foram disponibilizadas pelo Instituto de Meio Ambiente e Recursos Hídricos do Estado do Espírito Santo (IEMA) e possuem escala de 1:35.000, referente ao aerolevantamento, e de 1:15.000, referente ao ortofotomosaico, composto por imagens digitais no formato GeoTIFF, com resolução espacial de um metro. O padrão de exatidão cartográfica das imagens é considerado alto (classe A), com erro de posicionamento máximo de 7,5 m.

Para a delimitação das APPs, utilizaram-se dados cartográficos advindos das cartas digitais de altimetria (curvas de nível) e de hidrografia, oriundas do Instituto Brasileiro de Geografia e Estatística (IBGE), folha SF-24-V-A-V-2, em escala de 1:50.000. O Modelo Digital de Elevação (MDE) do terreno, em formato matricial (raster), com resolução espacial de $10 \mathrm{~m}$, foi elaborado a partir da interpolação das curvas de nível utilizando o interpolador Topo To Raster, do programa computacional ArcGIS, com suporte da hidrografia digitalizada orientada na direção do escoamento (Stream), conforme indicado por Pires et al. (2005). O pós-processamento consistiu da eliminação de espúrias do MDE por filtragem (Fill), obtendo-se o Modelo Digital de Elevação Hidrologicamente Consistente (MDEHC) da BRP. Posteriormente, foi aplicada a metodologia de delimitação automática de bacias hidrográficas descrita por Santos (2007) e Medeiros et al. (2009).

Com base nos critérios determinados na legislação pertinente, as APPs foram delimitadas, em ambiente de SIG, a partir das representações cartográficas de hidrografia e do relevo, sendo este representado pelo MDEHC. Adotou-se a seguinte sequência de procedimentos para delimitação das áreas de preservação da BRP:
- Nos topos de morros e montanhas: as APPs foram demarcadas a partir do MDEHC, utilizandose o programa SPRING (MNT - Extração de Topos), pela categoria numérica ativa e pela indicação de uma categoria temática para geração da delimitação. Adotou-se o modelo grade, indicando os valores de cota mais alto e mais baixo da elevação, sendo a delimitação referente ao terço superior dos referidos topos, gerada automaticamente pelo sistema (Câmara et al., 1996);

- Nas encostas com declividade superior a $45^{\circ}$ : a partir do MDEHC, gerou-se o mapa de declividade da bacia no ArcGIS, em graus, e selecionaram-se as referidas áreas utilizando a ferramenta Raster Calculator;

- Nas margens dos cursos d'água: gerou-se no ArcGIS um Buffer a partir do arquivo vetorial com os cursos d'água da BRP. Considerando-se que todos os cursos d'água da bacia possuem largura inferior a $10 \mathrm{~m}$, adotou-se a largura de $30 \mathrm{~m}$ para o Buffer, para cada lado;

- Ao redor de nascentes: as APPs foram delimitadas a partir da criação de um arquivo vetorial de pontos, o qual foi editado utilizando-se a ferramenta Edit, com auxílio da opção Snapping, visando a selecionar as extremidades das linhas de hidrografia com cotas mais elevadas, nas quais se localizam as nascentes. A partir da identificação pontual das nascentes, gerou-se um Buffer de 50 $\mathrm{m}$ de raio para todos os pontos (Santos, 2007);

- APP total: determinada a partir da junção de todos os polígonos, obtidos pelos diferentes critérios anteriormente descritos, utilizando o recurso Dissolve do ArcGIS. Tal procedimento possibilitou a delimitação e a mensuração de toda a área prevista para preservação, com exclusão das eventuais sobreposições espaciais de APPs na sub-bacia.

A partir dos arquivos vetoriais obtidos com o mapeamento das APPs e das classes de uso da terra na sub-bacia, procedeu-se ao cruzamento de tais informações (mapas temáticos) no ArcGIS, visando a avaliar a situação das APPs, com relação às possíveis ocorrências de conflito de uso dessas áreas.

\section{RESULTADOS E DISCUSSÃO}

Na Figura 2, apresenta-se a distribuição espacial dos tipos de uso da terra na sub-bacia hidrográfica do Rio da Prata, obtida a partir da digitalização das feições identificadas nas fotografias aéreas 


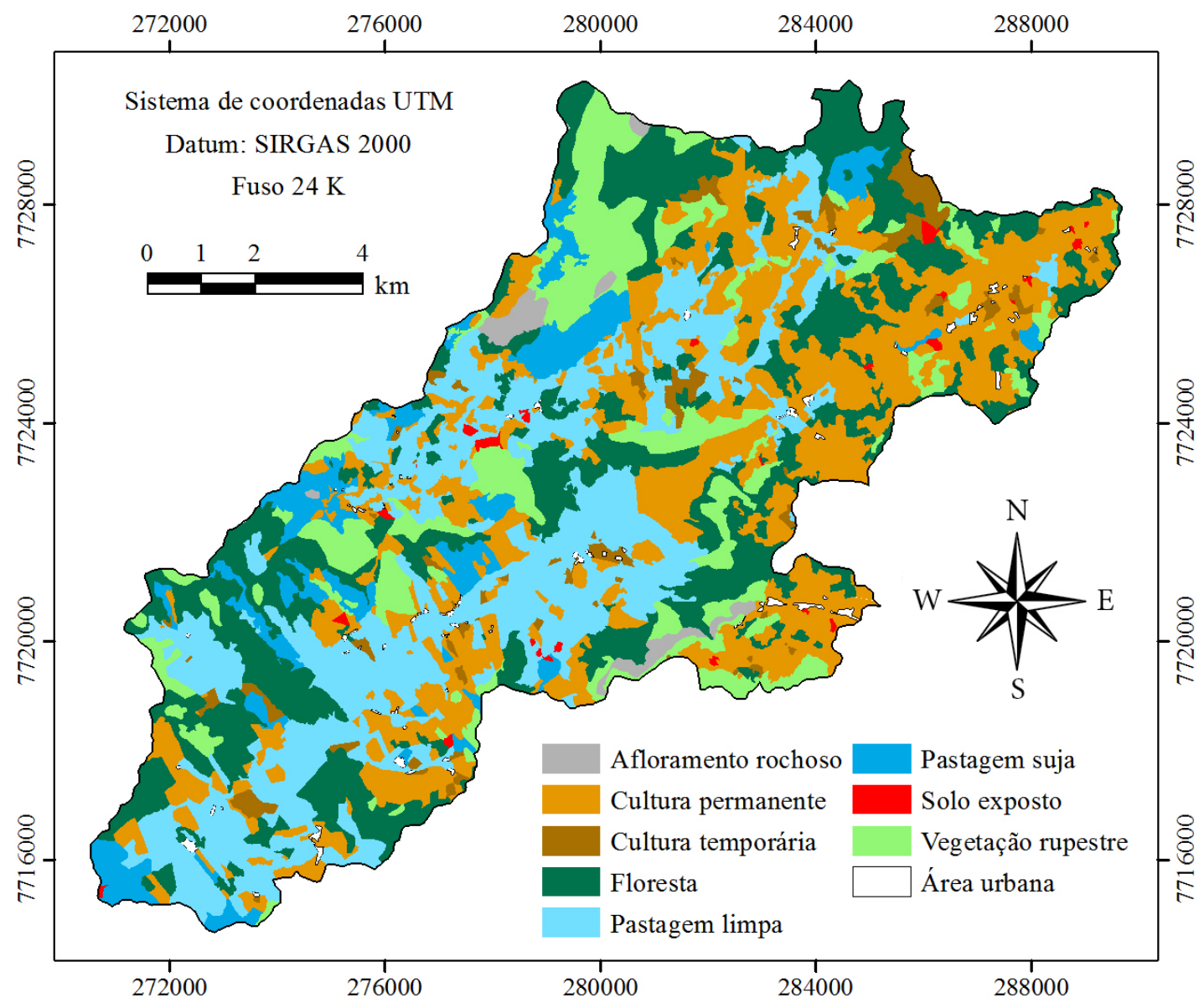

Figura 2. Distribuição espacial dos tipos de uso da terra na sub-bacia hidrográfica do Rio da Prata, município de Castelo, Estado do Espírito Santo.

Figure 2. Spatial distribution of the types of land use at Prata River watershed, Castelo county, Espírito Santo state, Brazil.

(fotointerpretação). A situação atual do uso da terra na sub-bacia, conforme apresentado na Figura 2, resultou do desmatamento da Mata Atlântica para expansão da fronteira agropecuária, muitas vezes em áreas que, sob o ponto de vista ambiental, deveriam ser destinadas à preservação.

Entretanto, ressalta-se que grande parte dos desmatamentos ocorreu antes da aprovação do Código Florestal de 1965. De acordo com Campos Júnior (1996), as lavouras de café cresceram significativamente até 1897; mas, em função da crise do café (1910-1964), foram gradativamente substituídas por pastagens. Coutinho e Sampaio (2007) avaliaram a situação da vegetação na Bacia do Rio Itapemirim entre os anos de 1977 e 2006, a partir do tratamento de imagens orbitais, concluindo que $61 \%$ da vegetação nativa da área havia sido suprimida até o auge da crise do café (1964) e que 20,81\% foram suprimidos durante o período analisado, via imagens orbitais.

Adicionalmente, na Tabela 1, encontram-se os valores de área e a porcentagem das classes de uso da terra na BRP. Observa-se que há predominância de uso da terra com pastagens $(30,63 \%)$, incluindo as áreas limpas e sujas, seguidas de atividades agrícolas $(30,21 \%)$, incluindo as culturas permanentes e temporárias. Margens de rios, que deveriam ser destinas à preservação, encontram-se ocupadas por agropecuária. Os remanescentes de vegetação nativa (floresta e vegetação rupestre) se encontram em áreas de difícil acesso ou de solos rasos. Pode-se observar, ainda, certo equilíbrio entre as áreas utilizadas com atividades agrícolas e pecuárias na sub-bacia. 
Tabela 1. Uso da terra na sub-bacia hidrográfica do rio da Prata, município de Castelo, Estado do Espírito Santo.

Table 1. Land use at Prata river watershed, Castelo county, Espírito Santo state, Brazil.

\begin{tabular}{lcc}
\multicolumn{1}{c}{ Classe } & Área $\left(\mathbf{k m}^{\mathbf{2}}\right)$ & Área (\%) \\
\hline Afloramento rochoso & 1,55 & 1,18 \\
Cultura permanente & 36,05 & 27,26 \\
Cultura temporária & 3,84 & 2,95 \\
Área urbana & 0,86 & 0,61 \\
\hline Floresta & 32,60 & 24,68 \\
\hline Pastagem limpa & 31,66 & 24,01 \\
\hline Pastagem suja & 8,80 & 6,62 \\
\hline Solo exposto & 0,72 & 0,52 \\
\hline Vegetação rupestre & 16,20 & 12,17 \\
\hline
\end{tabular}

As classes referentes a afloramento rochoso, área urbana (edificações) e solo exposto foram as que apresentaram as menores áreas de ocupação na BRP, em ordem decrescente, totalizando apenas $2,31 \%$ de sua área total.

Louzada et al. (2009), avaliando uma sub-bacia hidrográfica vizinha, referente ao Ribeirão Estrela do Norte, localizada nos municípios de Castelo e Cachoeiro de Itapemirim- ES, verificaram que $33,10 \%$ da área total era utilizada com pastagem e $12,40 \%$, com culturas agrícolas. Já Nascimento et al. (2005), avaliando a sub-bacia do Rio Alegre, em Alegre-ES, localizada na mesma macrorregião deste estado, constataram que $68,52 \%$ da área era ocupada por pastagens, incluindo pastagem suja, e que 11,52\% eram utilizados com atividades agrícolas, incluindo as áreas com cafeicultura. Pode-se observar, portanto, que as áreas utilizadas com agricultura e pecuária podem apresentar diferenças expressivas, mesmo em municípios próximos, devidas às aptidões e tradições de uso da terra, dentre outros fatores.

A Macrorregião Sul do Estado do Espírito Santo passou pelo processo de supressão da vegetação natural pelas atividades antrópicas, motivo pelo qual há predominância de uso e ocupação do solo com atividades agropecuárias, representado cerca de $60 \%$ da área total da BRP. Entretanto, esta proporção pode apresentar variações expressivas como, por exemplo, nas sub-bacias estudadas por Louzada et al. (2009) e Nascimento et al. (2005), com aproximadamente $45 \%$ e $80 \%$ de suas áreas ocupadas pela agropecuária, respectivamente.

Com relação à cobertura florestal nativa, a BRP apresenta $36,85 \%$ de sua área preservada, incluindo vegetação rupestre. Louzada et al. (2009) e Nascimento et al. (2005), nos estudos supracitados, verificaram que $41,17 \%$ e $16,16 \%$ da cobertura florestal das sub-bacias avaliadas encontra-se preservada, incluindo as vegetações denominadas de intermediária e capoeira, respectivamente.

A partir de procedimentos automatizados, utilizando técnicas de SIG, foram delimitadas e quantificadas as APPs na BRP. Na Figura 3, ilustrase a distribuição espacial de todas as APPs, obtidas pela fusão das diferentes categorias consideradas no presente estudo.

De forma complementar, as áreas de cada tipo de APP - com eventuais sobreposições de diferentes tipos de APP na mesma área - e o total geral são apresentados na Tabela 2. Pode-se observar que a APP predominante refere-se às áreas com declividade superior a $45^{\circ}$, seguidas dos topos de morros e montanhas, margens dos cursos d'água e ao redor de nascentes. Louzada et al. (2009) e Eugenio et al. (2011), estes analisando as APPs de todo o município de Alegre-ES, obtiveram maior proporção de APPs na categoria topos de morro $(23,53 \%$ e $30,69 \%$, respectivamente), seguidos de margens de cursos d'água ( $15,93 \%$ e $12,30 \%$, respectivamente). No presente estudo, obteve-se maior proporção de APPs em encostas com declividade superior a $45^{\circ}$ devido ao fato de a BRP possuir relevo mais montanhoso.

Coutinho (2010) simulou as perdas de solo por erosão hídrica (ton/ha/ano) na BRP a partir da adequação da Equação Universal de Perdas de Solo (EUPS), em ambiente de SIG. Foram identificados valores de média $(85,43)$ e máxima $(3.817,55)$, em condições de uso real do solo e com respeito às APPs (média: 27,50 e máxima: 996,86). Tais dados expressam a importância das APPs e de sua respectiva vegetação, para a qualidade dos solos e a produção de água em bacias hidrográficas.

Como se pode observar, $55,48 \%$ da área total da BRP é considerada APP, de acordo com os critérios estabelecidos no Código Florestal vigente. Esta proporção é ligeiramente superior aos valores encontrados por Louzada et al. (2009) e Eugenio et al. (2011), de $41,12 \%$ e 43,5\%, respectivamente. A quantidade total de APPs em uma região, bem como a distribuição de seus diversos tipos, depende, além do relevo, da disponibilidade de mananciais 


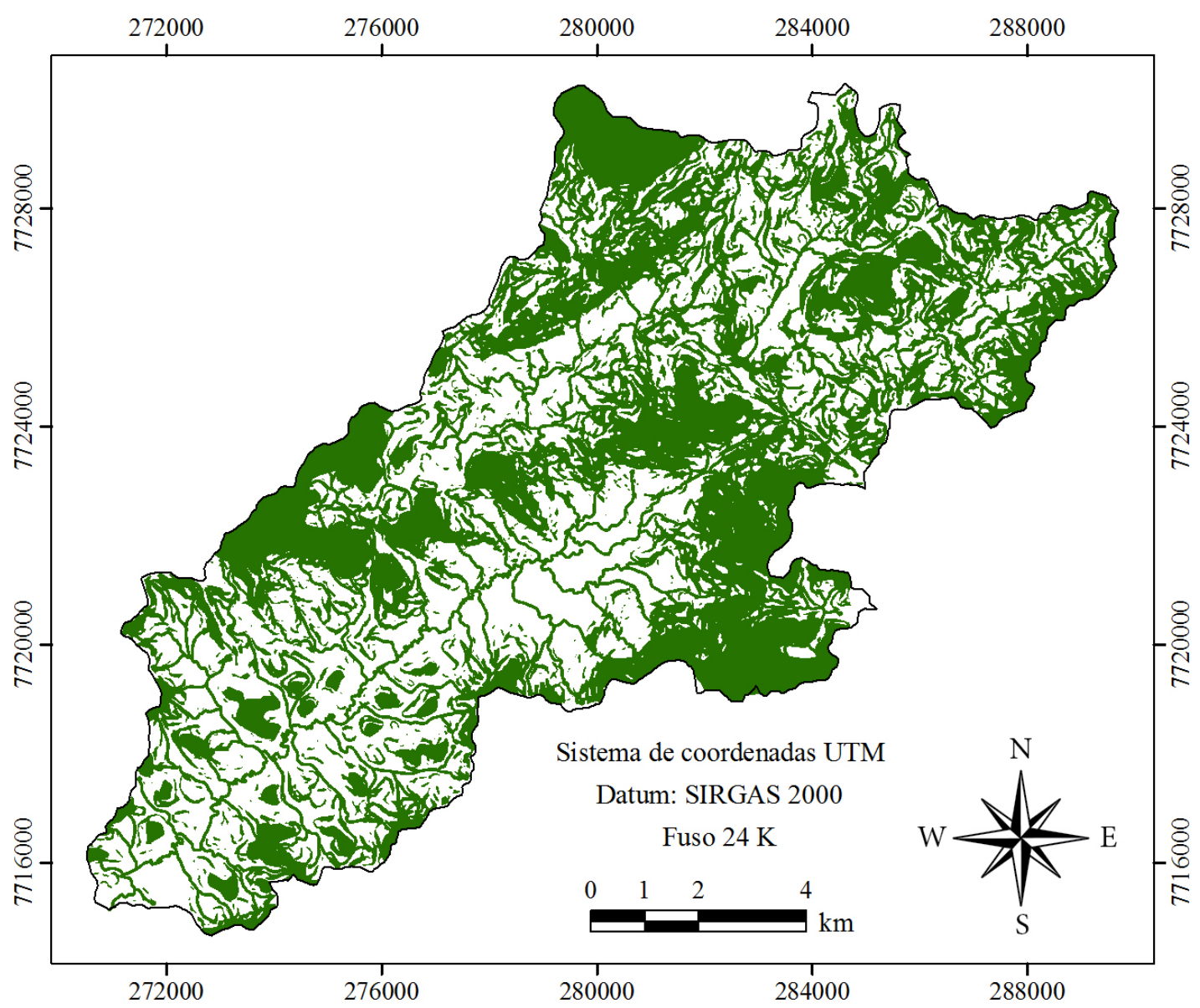

Figura 3. Distribuição espacial das Áreas de Preservação Permanente (APPs) na sub-bacia hidrográfica do Rio Prata, município de Castelo, Estado do Espírito Santo.

Figure 3. Spatial distribution of the Permanent Preservation Areas (APPs) in the Prata river watershed, Castelo county, Espírito Santo state, Brazil.

hídricos existentes, como cursos d'água e nascentes. A combinação destes fatores favoreceu a ocorrência de uma maior proporção de APPs na BRP.

Somando-se as APPs com a área mínima obrigatória da Reserva Legal nesta região do País (20\%), chega-se à expressiva proporção de 75,58\% da área total da BRP que deve ser preservada com a manutenção da cobertura florestal. Assim, a área passível de utilização para execução de atividades produtivas é expressivamente reduzida, sendo inferior a $25 \%$ da área total da sub-bacia. Este fato pode dificultar o cumprimento das funções social e econômica das propriedades rurais, no contexto do desenvolvimento sustentável.

A partir do cruzamento das informações contidas nas Figuras 2 e 3, referentes à distribuição
Tabela 2. Áreas de Preservação Permanentes (APPs) da sub-bacia hidrográfica do Rio da Prata, município de Castelo, Estado do Espírito Santo.

Table 2. Permanent Preservation Areas (APPs) in the Prata river watershed, Castelo county, Espírito Santo state, Brazil.

\begin{tabular}{lcc}
\multicolumn{1}{c}{ APPs } & $\begin{array}{c}\text { Área total } \\
\left(\mathbf{k m}^{\mathbf{2}} \mathbf{)}\right.\end{array}$ & $\begin{array}{c}\text { Área total } \\
\mathbf{( \% )}\end{array}$ \\
\hline Ao redor de nascentes & 1,65 & 1,25 \\
\hline Margens de cursos d'água & 16,95 & 12,81 \\
\hline Topos de morro e montanhas & 21,65 & 16,37 \\
\hline Áreas com declividade $>45^{\circ}$ & 49,06 & 37,09 \\
\hline APP total (sem sobreposições) & 73,39 & 55,48 \\
\hline
\end{tabular}

espacial das classes de uso da terra e das APPs na $\mathrm{BRP}$, respectivamente, obteve-se o mapa temático apresentado na Figura 4. Por meio desta análise espacial, constatou-se que apenas $49,60 \%$ das 


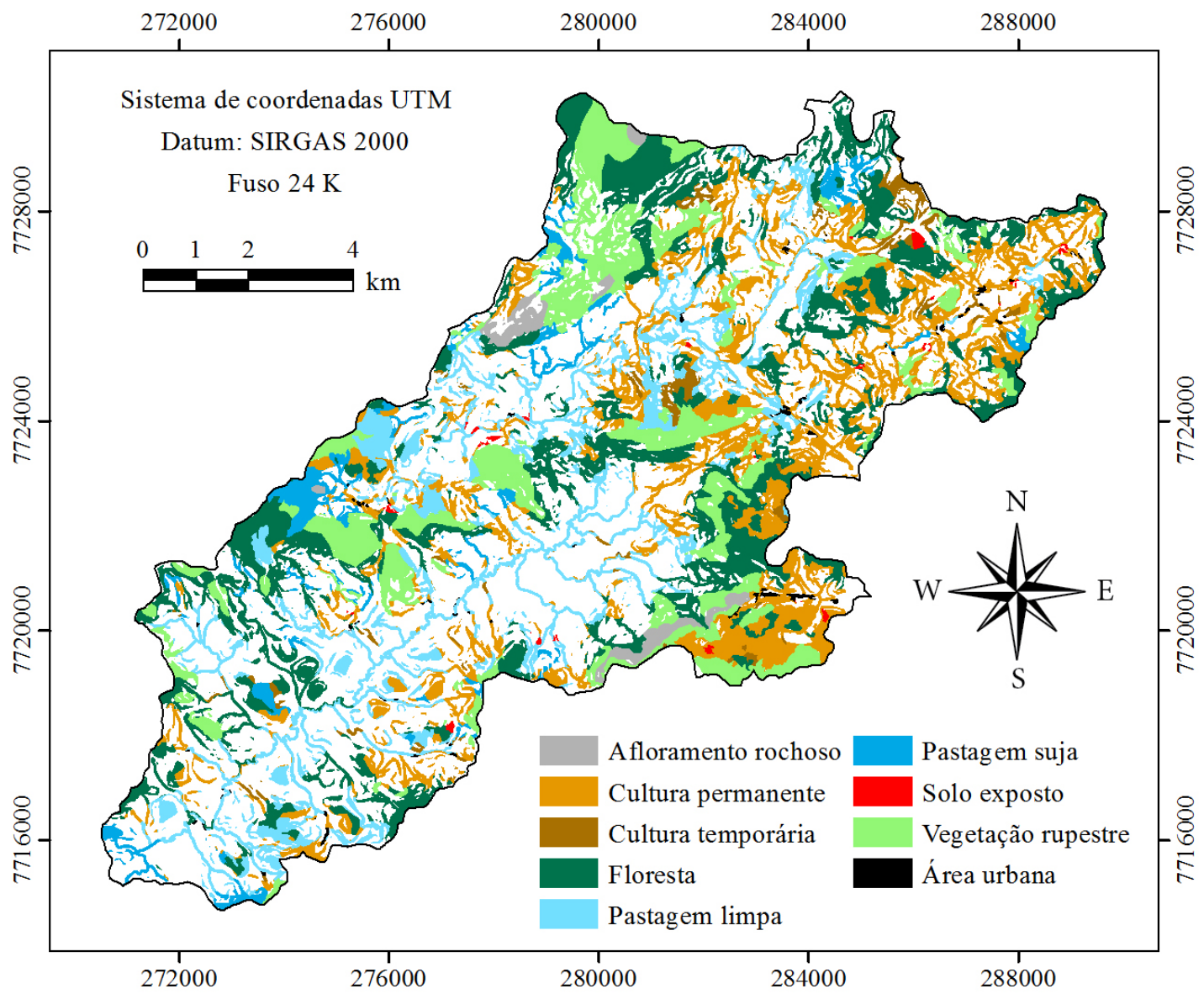

Figura 4. Uso da terra nas Áreas de Preservação Permanentes (APPs) da sub-bacia hidrográfica do Rio da Prata, município de Castelo, Estado do Espírito Santo.

Figure 4. Land use in the Permanent Preservation Areas (APPs) of Prata river watershed, Castelo county, Espírito Santo state, Brazil.

APPs estão sendo realmente preservadas com a manutenção da cobertura florestal nativa ou com superfície rochosa. Ou seja, 50,40\% das APPs da subbacia estão sendo utilizadas para fins econômicos ou ocupacionais, contrariando a legislação ambiental. Destas, as atividades agrícolas - permanentes e temporárias - ocupam 27,07\%, seguidas das pastagens - limpas e sujas -, com ocupação de $22,52 \%$. As áreas de solo exposto e zona urbana possuem as menores taxas de ocupação, em ordem decrescente.

De acordo com a Resolução n. ${ }^{\circ} 303$ do CONAMA (Brasil, 2002), as APPs integram o desenvolvimento sustentável, objetivo das presentes e futuras gerações, sendo instrumentos de relevante interesse ambiental. Nesse contexto, a utilização de aproximadamente metade das APPs com atividades agropecuárias na BRP, conforme apresentado na Figura 4, pode ser um fator de comprometimento do uso sustentável da água e do solo, principalmente ao se considerar a dependência da agropecuária pela disponibilidade quantitativa e qualitativa destes recursos.

De acordo com Silva (2006), parte das dificuldades existentes sobre a real preservação das APPs se deve ao fato de a legislação ambiental utilizar os mesmos critérios para todo o País, quando se sabe que os ecossistemas brasileiros são muito diferentes, variando de região para região, inclusive com variações expressivas no relevo. Além disso, a legislação não faz nenhuma distinção das APPs em relação à área urbana e ao meio rural, que, também, constituem realidades e usos diferentes. Por isso, tais áreas devem ser tratadas de forma diferente, sob pena de continuarmos assistindo à degradação ambiental em detrimento de uma lei que não se aplica concretamente, pois diverge dos fatos e da realidade nacional. 


\section{CONCLUSÕES}

A principal forma de uso da terra na BRP refere-se à agropecuária, ocupando 60,84\% da área total, sendo composta pela agricultura, com ocupação de 30,21\%, e pela pecuária, com 30,63\%. A área preservada com Mata Atlântica nativa é de $36,85 \%$. Os demais tipos de uso apresentaram áreas relativamente inexpressivas.

As APPs representam 55,48\% da área total da BRP, de acordo com os critérios estabelecidos no Código Florestal vigente. As categorias predominantes na sub-bacia, em ordem decrescente, são as áreas com declividade superior a $45^{\circ}$, seguidas dos topos de morros e montanhas, das margens dos cursos d'água e ao redor de nascentes.

A maior parte das APPs da BRP (50,40\%) está sendo utilizada com finalidades econômicas ou ocupacionais. Nesse aspecto, as atividades agrícolas são as mais expressivas, utilizando 27,07\% das APPs, seguidas da pecuária, com ocupação de 22,52\%.

Com base na legislação ambiental vigente, a maior parcela das APPs da Bacia do Rio da Prata é utilizada de forma indevida. Faz-se necessária a adoção de medidas reguladoras das atuais formas de uso e ocupação da terra, pois a falta de preservação dessas áreas pode surtir efeitos negativos sobre os recursos naturais. Espera-se que os procedimentos de delimitação e avaliação de APPs, em ambiente de SIG, possam nortear as demais formas de aplicação.

\section{STATUS DA SUBMISSÃO}

Recebido: 23/07/2012

Aceito: 09/10/2013

Publicado: 31/12/2013

\section{AUTOR(ES) PARA CORRESPONDÊNCIA}

\section{Luciano Melo Coutinho}

Curso de Ciências Biológicas, Centro

Universitário São Camilo-ES, CEP 29304-910,

Cachoeiro de Itapemirim, ES, Brasil

e-mail: lcncoutinho@hotmail.com

\section{REFERENNCIAS}

Brasil. Ministério do Meio Ambiente. Lei no 4.771, de 15 de setembro de 1965. Institui o Código Florestal Brasileiro. Diário Oficial da República Federativa do Brasil, Brasília, DF (1965 set.).

Brasil. Ministério das Minas e Energia. Secretária Geral. Projeto RADAMBRASIL. Levantamentos dos Recursos Naturais - Folha SF 23-24; Geologia, Geomorfologia, Pedologia, Vegetação, Uso potencial da Terra. Rio de Janeiro: IBGE, 1983.

Brasil. Ministério do Meio Ambiente. Resolução n 303, de 20 de março de 2002. Dispõe sobre parâmetros, definições e limites de Áreas de Preservação Permanente. Diário Oficial da República Federativa do Brasil, Brasília, DF (2002 mar.).

Câmara G, Souza RCM, Freitas UM, Garrido J. SPRING: Integrating remote sensingand GIS by object-oriented data modelling. Computers \& Graphics 1996; 20(3): 395 403. http://dx.doi.org/10.1016/0097-8493(96)00008-8

Campos Júnior CT. O Novo Arrabalde. Vitória: Prefeitura Municipal de Vitória, Secretaria Municipal de Cultura e Turismo; 1996. 250 p

Castro Júnior RM, Sobreira FG, Bortoloti FD, Souza LA. Definição de unidades geomorfológicas a partir de navegação e validação de campo utilizando GPS e sistemas de informações geográficas: o caso as subbacia do rio Castelo-ES. Boletim de Ciências Geodésicas 2007; 13(1): 42-59.

Coutinho LM. Impacto das áreas de preservação permanente sobre a erosão hídrica na bacia hidrográfica do Rio da Prata, Castelo-ES [dissertação]. Jerônimo Monteiro: Universidade Federal do Espírito Santo; 2010.

Coutinho LM, Sampaio TVM. Evolução da supressão de florestas na bacia hidrográfica do Rio Itapemirim via uso de imagens orbitais. Revista Camiliana de Iniciação Científica 2007; 2(1): 156-163.

Eugenio FC, Santos AR, Louzada FLRO, Pimentel LB, Moulin JV. Identificação de áreas de preservação permanente no município de Alegre utilizando geotecnologia. Cerne 2011; 17(4): 563-571.

Hott MC, Guimarães M, Miranda EE. Método para a determinação automática de áreas de preservação permanente em topos de morros para o Estado de São Paulo, com base em geoprocessamento. Campinas: Embrapa Monitoramento por Satélites; 2004.

Lima WP. Hidrologia florestal aplicada ao manejo de bacias hidrográficas. Piracicaba: ESALQ; 2008.

Louzada FLRO, Santos AR, Sattler MA. Análise das áreas de preservação permanentes da bacia hidrográfica do ribeirão Estrela do Norte, ES. Revista de Biologia e Saúde 2009; 3(2): 128-141. 
Medeiros LC, Ferreira NC, Ferreira LG. Avaliação de modelos digitais de elevação para delimitação automática de bacias hidrográficas. Revista Brasileira de Cartografia 2009; 61(2): 137-151.

Nascimento MC, Soares VP, Ribeiro CAAS, Silva E. Uso do geoprocessamento na identificação de conflito de uso da terra em áreas de preservação permanente Bacia Hidrográfica do Rio Alegre, Espírito Santo. Ciência Florestal 2005; 15(2): 207-220.

Pinto LVA, Ferreira E, Botelho AS, Davide AC. Caracterização física da bacia hidrográfica do ribeirão santa cruz, Lavras, MG e uso conflitante da terra em suas áreas de preservação permanente. Cerne 2005; 11(1): 49-60.

Pires JM, Nascimento MC, Santana RM, Ribeiro CAAS. Análise da exatidão de diferentes métodos de interpolação para geração de modelos digitais de elevação e obtenção de características morfométricas em bacias hidrográficas. Revista Brasileira de Recursos Hídricos 2005; 10(2): 39-47.

Ribeiro CAAS, Soares VP, Oliveira MAS, Gleriani JM. O desafio da delimitação de áreas de preservação permanente. Revista Árvore 2005; 29(2): 203-212. http://dx.doi.org/10.1590/S0100-67622005000200004
Santos AR. ArcGIS 9.1 total: aplicações para dados espaciais. Vitória: Fundagres; 2007.

Silva JM. Programa levantamentos geológicos básicos do Brasil. Brasília: DNPM/CPRM; 1993. Cachoeiro de Itapemirim - Folha SF-24-V-A-V. Estado do Espírito Santo, escala 1:100.000.

Silva VG. Legislação ambiental comentada. 3. ed. Belo Horizonte: Fórum; 2006.

Soares VP, Moreira AA, Ribeiro CAAS, Gleriani JM. Mapeamento das áreas de preservação permanente e dos fragmentos florestais naturais como subsidio à averbação de Reserva Legal em imóveis rurais. Cerne 2011; 17(4): 555-561.

Vicente CRB, Simões ERD, Moreira JVP, Fonseca MA. Inventário da oferta turística do município de Castelo. Serviço de Apoio às Micro e Pequenas Empresas Espirito Santo; 2005.

Vieira MV, Peluzio TMO, Saito NS, Souza SM, Louzada FLRO, Santos AR. Delimitação das áreas de preservação permanente do terço superior de topo de morro, para as microrregiões sudoeste serrana, litoral norte e extremo norte do estado do Espírito Santo. Revista Brasileira de Agroecologia 2011, 6(2): 142-151. 